\title{
ENTRE EL MENSAJE ROMÁNTICO Y EL ETNOROCK EN YOUTUBE: REPERTORIOS IDENTITARIOS EN LOS PAISAJES VIRTUALES DE JÓVENES MAYAS TSOTSILES
}

\author{
Between Romantic Texting and Ethnorock on YouTube: Repertoires \\ of Identity in the Virtual Landscapes of Tsotsil Mayan Youth
}

\author{
Lourdes de León-Pasquel
}

Resumen: En el estudio se examina el uso de las tecnologías digitales por jóvenes de origen tsotsil, principalmente a través de mensajes de texto por celular y de intercambios en páginas de YouTube de grupos musicales. Se analizan los "paisajes virtuales" como nuevas formas de afectividad, socialización y sociabilidad desde un enfoque etnográfico, semiótico y sociolingüístico. Estos paisajes se caracterizan por ser el vehículo de expresiones identitarias de culturas juveniles étnicas. La investigación aporta al campo de las juventudes étnicas desde ángulos escasamente investigados en América Latina, el de la sociolingüística de la globalización y el de las literacidades digitales prácticas.

Palabras clave: teléfono celular, redes sociales, comunicación digital, identidad, jóvenes, mayas, cultura, globalización.

Abstract: This study examines the use of digital technologies (primarily cell phones) by Tsotsil Mayan youth in the form of texts (SMS), as well as other interchanges on YouTube websites of Tsotsil musical groups. My analysis addresses "virtual landscapes" as new forms of peer socialization and sociability from an ethnographic, semiotic, and sociolinguistic approach. These landscapes can be characterized as vehicles for identity expressions of ethnic youth cultures. I conclude that media youth identities are configured by the reciprocal development of macro-social processes and emergent and situated communicative practices in everyday digital interchanges.

Keywords: cell phone, social networks, digital communication, youth, identity, Mayan, culture, globalization.

Lourdes de León Pasquel. Doctora en Lingüística por la Universidad de Sussex, Gran Bretaña. Profesora-investigadora del Centro de Investigaciones y Estudios Superiores en Antropología Social (CIESAS), México. Temas de especialización: socialización lingüística, discurso, infancia, juventud, comunicación digital, bilingüismo, aprendizaje comunitario, lenguas mayas (tsotsil). Correo electrónico: lourdesdeleonp@gmail.com.
Enviado a dictamen: 6 de abril de 2017

Aprobación: 25 de octubre de 2017.

Revisiones: 1. 


\section{Introducción}

E n un reporte reciente de la Encuesta Nacional sobre Disponibilidad y Uso de las Tecnologías de la Información en los Hogares (ENDUTIH) del Instituto Nacional de Geografía y Estadística (INEGI, 2016) se indica que la telefonía celular es la red de mayor penetración en México y la que presenta menores diferencias entre regiones en cuanto a su uso, en contraste con las tecnologías de información y comunicación (TIC) como el WiFi, ${ }^{1}$ las computadoras y otros recursos de conectividad, cuyo uso presenta diferencias regionales mayores. En el país, los estados de Oaxaca, Guerrero y Chiapas son los que muestran el porcentaje más bajo de disponibilidad de teléfono celular dado que el promedio de uso de este recurso de comunicación entre la población es del 55\% (De León, 2017a). Es en estos estados donde se concentra más población indígena del país: iqué representa el uso del celular en estas regiones?

En el estado de Chiapas se registra el mayor índice de analfabetismo y el menor de escolaridad en todo México (INEGI, 2015). Estos bajos índices se concentran en las generaciones mayores y contribuyen a la existencia de una marcada brecha digital entre generaciones que ha sido documentada en varios estudios como un fenómeno general (Clark, 2009). En comunidades indígenas esta brecha digital representa una profunda reconfiguración de las identidades jóvenes con respecto a las generaciones mayores, en términos, sobre todo, de la relación con la comunidad histórica y la lengua. Entre otros procesos, las fronteras físicas comunitarias se desdibujan con la emergencia de comunidades de práctica virtuales que se caracterizan por formas nuevas de socialización y sociabilidad.

Tener acceso a la comunicación por celular implica adquirir un objeto cultural, entrar a un mercado de consumo, adquirir prácticas culturales y comunicativas nuevas y, en algunas comunidades étnicas históricas, desarrollar nuevas afectividades como cortejar, amar y elegir pareja en las redes invisibles virtuales que los adultos analfabetos no imaginan ni controlan. En este sentido, se registra la emergencia de una cultura juvenil que crea, recrea, resiste y reconfigura su identidad en la intersección de las culturas juveniles globalizadas y las culturas juveniles étnicas. A su vez, se advierten nuevos espacios de socialización entre grupos de pares juveniles que participan de las prácticas mediáticas de culturas juveniles globales - uso de mensajes de texto (SMS, por las siglas del inglés Short Message Service), ${ }^{2}$ WhatsApp, ${ }^{3}$ Facebook, MySpace, YouTube ${ }^{4}$ y otras redes sociales - que crean sus propios referentes locales y culturales. Detrás de estos procesos surgen algunas preguntas como las siguientes: ¿cómo se ha incorporado la nueva tecnología del celular en la vida comunicativa de las familias de las comunidades históricas indígenas?; en el contexto de la comunicación mediática, ¿cómo configuran y reconfiguran los jóvenes indígenas aquellos elementos que los vinculan con sus raíces identitarias como la lengua, la etnicidad, las prácticas culturales y la comunidad histórica? o icuál es la naturaleza de los paisajes virtuales de los jóvenes tsotsiles y qué expresan en la conformación de una cultura juvenil mediática?

En el presente artículo se examinan comunicaciones digitales escritas por jóvenes de comunidades de origen tsotsil —del municipio de Zinacantán, hablantes de tsotsil- en recursos virtuales como mensajes de texto (SMS,) o en los espacios colectivos de las redes sociales. Para este fin parto del concepto de "paisaje lingüístico virtual", acuñado por el sociolingüista de la globalización Jan Blommaert, que se refiere a los mensajes "escritos" desplegados en los espacios virtuales y físicos que, por su naturaleza situada, tienen rasgos de intercambios orales (Blommaert, 2010: 173). ${ }^{5}$ En la misma línea, Mendoza Denton (2016) investigó lo que llamó "paisajes virtuales" (virtual landscapes), de manera independiente a Blommaert $(2010,2013)$, en su estudio sobre identidades y territorialidades virtuales de las pandillas mexicanas en Estados Unidos en sus comunicaciones en páginas de YouTube.

La noción de "paisaje virtual" tiene como antecedente los conceptos acuñados por Appadurai, en su estudio sobre la modernidad y la globalización, en lo que llamó los "etnopaisajes" (ethnoscapes), los "paisajes mediáticos" (mediascapes), los "tecnopaisajes" (technoscapes) y los 
"ideopaisajes" (ideoscapes) que navegan y traspasan fronteras en el mundo global (Appadurai, 1996: 33).

En el presente trabajo retomo la noción de "paisaje virtual" de manera genérica y lo abordo en los siguientes términos: 1) es una forma de escritura situada mediática, 2) es el vehículo de formas y expresiones identitarias de culturas juveniles étnicas y 3) se constituye en "repertorios identitarios" (Kroskrity, 1993). Para Kroskrity, los repertorios de identidad se refieren al proceso por el cual "las identidades son invocadas interactivamente por actores socioculturales a través del despliegue discursivo de los recursos lingüísticos" (1993: 222). Este enfoque aporta a la propuesta de que las identidades de los jóvenes son configuradas por procesos culturales y políticos no sólo a gran escala, sino, de manera importante, en el nivel local de las prácticas comunicativas emergentes y situadas. En este sentido, el estudio se adscribe en un enfoque semiótico y sociolingüístico que toma el lenguaje - verbal y visual - como recurso primario en la configuración de identidades y como vehículo que intermedia la experiencia social local y la translocal (Bucholtz y Skapoulli, 2009: 2). Lo anterior permite analizar cómo los actores configuran sus paisajes identitarios en intercambios semióticos microscópicos y su interrelación con procesos macrosociales más amplios. Para el análisis a nivel micro que se desarrolla en este trabajo se utilizan unidades discursivas dialógicas escritas en intercambios virtuales, sea en mensajes de celular o en intercambios de redes sociales. El nivel macro apunta al contexto cultural y político en el que se inscriben e inciden estos intercambios.

La articulación de niveles micro y macro permite también entender las "ecologías de la comunicación" que se definen por integrar de manera holística las interrelaciones entre dimensiones sociales, discurso y tecnologías de la comunicación (Foth y Hearn, 2007: 9). ${ }^{6}$

Se inicia el texto con la presentación de un panorama general, para luego analizar y caracterizar las prácticas mediáticas de jóvenes en mensajes de texto en celular y en páginas de YouTube de grupos musicales juveniles de afiliación tsotsil. Posteriormente se realiza un análisis semiótico de los paisajes virtuales en la creación de nuevos espacios de afectividad, sociabilidad y socialización. Y, para finalizar, se tejen los hilos que conforman los repertorios identitarios de las nuevas culturas mediáticas de jóvenes tsotsiles en sus intercambios locales y translocales, así como en sus articulaciones macro-sociales.

\section{El estudio}

El estudio se basa en un proyecto en curso sobre cambios en patrones y ecologías de comunicación en tres comunidades del municipio de Zinacantán (KN, JN, TN ${ }^{7}$ en Los Altos de Chiapas, y tiene sus raíces en más de tres décadas de investigación antropológica y lingüística en este municipio. ${ }^{8}$

Desde 2012 hasta 2017 se exploró sobre la entrada y la gradual inserción de la comunicación por celular en la vida cotidiana de estas comunidades, sus patrones y prácticas de uso en jóvenes y adultos, las elecciones lingüísticas — tsotsil o español- y la creación de códigos y géneros en mensajes de texto asociados con prácticas mediáticas juveniles. Más recientemente se comenzó a investigar la diversificación de paisajes virtuales entre los jóvenes en redes sociales, blogs y otros espacios virtuales, que en su mayoría son accesados desde el celular, dado que pocos jóvenes en estas comunidades cuentan con computadoras de uso personal.

Como han reportado muchos estudiosos de los grupos juveniles étnicos, estos son muy heterogéneos. Pueden ser de arraigo rural o urbano; sin escolarización o escolarizados a nivel incipiente, básico, medio o superior; con experiencia migratoria o sin ella, entre otros factores. El estudio de los mensajes de texto de celular en esta investigación se centra en jóvenes tsotsiles de arraigo rural en comunidades históricas de Zinacantán en Los Altos de Chiapas, con escolaridad incipiente y experiencia migratoria regional. El mayor número de jóvenes que intercambian mensajes en los sitios virtuales aquí documentados son de origen tsotsil, y no se cuenta con más detalles sobre sus trayectorias de vida además de las que aparecen en estos medios. 
El estudio en su forma extensa se desarrolló en tres fases. En la primera se combinaron tres métodos: 1) la etnografía de la comunicación en el entorno familiar, 2) entrevistas y cuestionarios a grupos etarios en el hogar y en escuelas secundarias y preparatorias de Zinacantán - cabecera- y de las dos comunidades del estudio, y 3) colección de una base de datos de tres mil mensajes de texto prepagados (entre 2012 y 2014) de diversos grupos etarios entre los 12 y los 45 años. En la segunda fase (2013-2016) se recolectaron 30000 mensajes de WhatsApp, de los cuales 10000 fueron analizados en un estudio de caso longitudinal de una pareja (edades 18 y 21) (De León, 2017b). En la tercera fase (2015 a 2017) se construye y se analiza una base de datos creada a partir de los intercambios que aparecen en las páginas en YouTube $^{9}$ de grupos musicales - Sak Tzevul, Lumaltok, Slajem K'op, Yibel Jme'tik Banamil一, Facebook y otros sitios de redes sociales de afiliación tsotsil.

La base de datos de mensajes de celular prepagados se constituyó con seis textantes focales (ego) de jóvenes pertenecientes a familias que la autora conoce desde hace más de tres décadas. Éstos interactúan con un número total de 175 textantes (alteri), de los cuales 93 son de sexo femenino y 84 de sexo masculino (entre 12 y 45 años de edad). Todos los mensajes fueron enviados o recibidos por miembros de la comunidad, y se obtuvieron con la autorización de los usuarios bajo el acuerdo de mantener el anonimato a través del uso de seudónimos e iniciales. ${ }^{10}$

Se analizó la base de datos de mensajes de texto en distintos niveles: a) forma - abreviaturas, códigos, léxico, ortografía - b) lengua utilizada — tsotsil o español-, c) estructura "conversacional", d) contenido temático, y e) tipo de género — por ejemplo, práctico, de juego, romántico- (De León, 2013b).

La segunda fase inició en 2013, cuando los jóvenes empezaron a adquirir teléfonos inteligentes y a tener conectividad con WiFi, por lo que sus prácticas comunicativas digitales se diversificaron. Comenzaron a acceder a WhatsApp, a redes sociales como Facebook y a videos musicales en YouTube, principalmente. En esta fase se documentó y analizó la base de datos de mensajes de WhatsApp.
Hacia fines de 2015 inició la tercera fase con la investigación de las comunicaciones digitales en las páginas de YouTube de grupos de diversos géneros musicales juveniles como rap, ska, y etnorock, ${ }^{11}$ así como en grupos de tipo religioso y comunitario, o en redes sociales como Facebook. Estas comunicaciones representaban intercambios con otros jóvenes tsotsiles locales, pero también del municipio y de otras comunidades regionales, nacionales y transnacionales. En este momento la comunidad histórica, física, se empezó a redibujar como una comunidad virtual en la que los participantes podían ser de la localidad, pero en gran parte eran de otras localidades y se encontraban reunidos alrededor de temas compartidos. Estos mensajes conformaron otra base de datos. Mientras los mensajes de texto y WhatsApp constituyen intercambios dialógicos, privados entre parejas, los de páginas de redes sociales constituyen comunidades virtuales públicas, nuevos espacios de socialización y de creación de repertorios lingüísticos e identitarios. En el curso de cinco años aproximadamente se atestiguó la emergencia de prácticas de sociabilidad y socialización novedosas, ligadas a la transformación del lenguaje situado en interacciones cara a cara con el nuevo lenguaje "móvil" que viaja por los medios (Blommaert, 2010). Se identificaron diversas expresiones de identidades emergentes, nuevas ideologías lingüísticas y mediáticas, nuevos géneros comunicativos escritos y la creación de códigos específicos al medio novedosos, entre otros procesos (De León, 2017b, en prensa).

En los mensajes de texto se registraron nuevas formas de sociabilidad afectiva privada entre parejas que expresaban romance, amor, cortejo e intimidad, lo que no se había registrado en las formas de sociabilidad tradicional en la vida cotidiana de la comunidad.

En las páginas públicas de las redes sociales se documentó la socialización entre pares juveniles a nivel colectivo. En un tiempo relativamente corto, estos procesos representaron la emergencia y configuración de nuevas culturas juveniles étnicas locales y translocales en los medios digitales. En el presente trabajo, se examina la base de datos de mensajes de texto y los mensajes colectivos en páginas virtuales públicas 
como parte de la gradual adopción del "lenguaje móvil" del celular y como expresión de nuevas formas de afectividad, sociabilidad y socialización entre los jóvenes del estudio.

\section{Las literacidades digitales y los nuevos repertorios de identidad}

Como han documentado varios estudiosos, los teléfonos móviles y la comunicación mediática son vehículos para crear, extender y transformar la sociabilidad en las redes de pares. ${ }^{12}$

En un estudio sobre el uso de los celulares en América Latina y el Caribe, De Angoitia y Ramírez (2009) reportaron el incremento de usuarios de bajos recursos en esta región y el costo que representa en su economía familiar. Los autores observaron que en los países del primer mundo los usuarios gastaban aproximadamente un 2\% y un 3\% de sus ingresos en servicios de telefonía móvil, mientras que, en contraste, en los países en desarrollo invertían entre el 10\% y el $40 \%$ (2009: 1). Sin embargo, es una realidad que, a cambio de este alto costo, este sector de la población mundial tiene acceso a información, así como a comunicación privada y pública.

Estudios en distintos países han mostrado la expansión masiva del uso de mensajes de texto a través del celular en una gran parte de la población del mundo que no tiene acceso a computadoras y WiFi. ${ }^{13}$

Es un hecho que el acceso a teléfonos inteligentes y la gradual expansión de la conectividad en beneficio de sectores de la población de bajos recursos trae consigo también el desarrollo de nuevas destrezas de alfabetismo y tecnológicas. Entre otros puntos, se identifica el desarrollo de "literacidades"14 (escrituras) digitales, también conocidas como tecno-literacidades. Se argumenta en este trabajo que tales literacidades están socialmente integradas y que articulan estructuras sociales mayores, como lo demuestran varios estudiosos del campo de las literacidades prácticas (Blommaert, 2008; Heath, 1983; Street, 2000). En el contexto del presente trabajo, estas prácticas de literacidad se analizan como vehículos para la exploración y la elaboración de procesos identitarios. Los interactuantes generan, comparten y socializan recursos semióticos que tienen el potencial de convertirse en repertorios de identidad (Kroskrity, 1993: 222), proceso que emerge en las interacciones textuales, a través de las cuales los jóvenes adoptan, prueban, negocian, disputan o resisten referentes identitarios. En consecuencia, en este contexto la identidad consiste en un proceso emergente resultado de un desarrollo creativo e interpretativo inscrito y mediado textualmente.

\section{Mensajes de texto en el celular y nuevas relaciones afectivas}

Un primer resultado del estudio realizado sobre el uso de los SMS prepagados revela que la mayoría de los jóvenes envía un número considerable de textos románticos en español, sólo con saludos y algunas partículas del discurso en tsotsil, porque en general argumentan que se comunican mejor en español y que el tsotsil "no se puede escribir", ideologías comúnmente adquiridas en el contexto escolar.

La nueva práctica de la comunicación a través de SMS es denominada en español por los jóvenes como "escribir mensaje" o "mensajear", lo que constituye un nuevo género híbrido que consiste en "hablar" mediante mensajes de texto. Muchas de las conversaciones reportadas en la base de datos de mensajes constituyen intercambios afectivos amorosos entre parejas. Los mensajes están escritos con códigos y abreviaturas en español usados en la comunidad hispana; por ejemplo se utiliza $k$ para "que", $t$ para "te", s para "es", $k$ 'ca' (Crystal, 2008).

Las relaciones amorosas que se desarrollan a través de "mensajear" tienen que ver sobre todo con mantener el canal afectivo fluyendo a través de saludos y de un habla romántica elaborada, que incluye apelativos amorosos - "mi amor", "mi bebé", "bombón", "flaquito", etcétera-, planes para encontrarse, casarse o, en algunos casos, fugarse con la pareja. De hecho, los textantes románticos pasan más tiempo enviándose mensajes de texto que hablando en encuentros cara a cara, puesto que en un espacio institucional como la 
escuela no pueden hacerlo, y en muchos hogares no se permite a las chicas salir solas, mucho menos de manera abierta con sus novios sin compañía.

El siguiente intercambio entre un chico y una chica —ambos de 19 años de edad—, revela cómo "mensajear" y hablar de "mensajear" mantiene el canal fluyendo. La chica terminó la primaria y el chico, la secundaria. Ella trabaja en casa con su familia y él viaja por el estado vendiendo flores.

De MV (19 años, novia, originaria de TN), a F (19 años, novio, originario de $\mathrm{TN})^{15}$

MV: aki sta konmigo mi mama luego mnsajeamos sk stoy asiéndo algo t amo muxo cuidat

[Aquí está conmigo mi mamá luego mensajeamos es que estoy haciendo algo, te amo mucho, cuídate]

En este intercambio la chica advierte al chico de que su madre puede estar vigilando sus mensajes de texto, así que le pide que se comuniquen más tarde. MV se refiere a su comunicación como "mensajear" ("mensajeamos"). El texto revela que las fronteras de los espacios habitados por la familia y los espacios virtuales compartidos por los jóvenes difícilmente se cruzan dado que los padres hablan poco español y, en muchos casos, son analfabetas o tienen poca escolaridad; es decir, los padres tienen control sobre el espacio físico, pero no sobre el virtual.

Asimismo, se observa una intensa sociabilidad que se manifiesta en saludos frecuentes para rectificar la presencia del otro. Los saludos presentan una mezcla de apelativos románticos que resuenan con el vocabulario de las telenovelas y canciones románticas mexicanas. El siguiente ejemplo muestra la frecuencia del uso de la palabra "amor" y de expresiones románticas que se escuchan con frecuencia en los medios:

De AT (16 años, chica, originaria de KN) a A (17 años, chico, originario de JN)

AT: Ola mi amor kmo amancist ya un pko mjor o sigues lo mismo t' amo ers mi gran amor nunca podría djat xk...Sin ti noc k pasaría kon mi vida

[Hola, mi amor, ¿cómo amaneciste?, ¿ya un poco mejor?, ¿o sigues lo mismo (igual)? Te amo, eres mi gran amor, nunca podría dejarte porque sin ti no sé qué pasaría con mi vida].

Textos de este tipo muestran la emergencia de un género nuevo - romántico, escrito-, ya que el lenguaje de amor romántico no se documenta en el vocabulario tsotsil convencional ni en las relaciones tradicionales en las comunidades del estudio (De León, 2017b), cuyas prácticas más comunes son la de pedir a la novia (jak'ol) o la de fugarse con el novio, ${ }^{16}$ por lo que no existe un período de noviazgo o de cortejo en espacios exclusivos para la pareja ni conversaciones de amor romántico, lo que se observó en los parajes del presente estudio.

Mensajes como el incluido en el siguiente ejemplo revelan también cómo este nuevo género romántico en la comunidad de estudio trae consigo la expresión de afectividades que dependen del medio digital, el contacto y el desencuentro que puede surgir de un mensaje no respondido:

De F (19 años, novio) a MVVP (19 años, novia) (1l de julio de 2012)

F: Que onda amor por que no me respondes te amo....... Que pasa amor ya no quieres que te mande mensajes dime

[¿Qué onda, amor, por qué no me respondes?, te amo... ¿Qué pasa, amor, ya no quieres que te mande mensajes?, dime]

En general, el texto romántico abre nuevas formas de crear, experimentar y manejar la intimidad con interlocutores semivirtuales o virtuales.

En otro estudio de la autora se analiza la evolución de los mensajes de texto prepagados a los de WhatsApp. En tanto esta última aplicación permite diálogos sin costo, las posibilidades de expresar el afecto y la intimidad son aún mayores. La exploración dialógica de estos espacios virtuales a un nivel más fino permite observar nuevas maneras de tejer identidades, subjetividades y afectividades no antes experimentadas.

En el presente estudio se explora la identidad por medio de procesos micro-discursivos cotidianos en los nuevos espacios virtuales de los jóvenes que conllevan 
la reconfiguración de afectividades, así como nuevas formas de agencia y de moralidades que redefinen las relaciones generacionales (Good, 2012). A pesar de la conquista de espacios privados separados del control parental, el camino a la independencia y la individualidad no es siempre directo ni liberador. En este sentido, las relaciones de género desfavorables para las chicas llevan, en muchas ocasiones, a situaciones en las que el idealismo romántico de los noviazgos por celular choca con la realidad de una vida de pareja inmersa en el sistema patriarcal bajo el control de la familia del hombre y, en especial, de la suegra. Este golpe de realidad trae consigo nuevas realineaciones entre las generaciones mayores, quienes reconocen la agencia de los jóvenes en sus mundos virtuales, pero que encasillan a las chicas en las normas patriarcales una vez que se casan, e incluso les prohíben usar el celular.

En general, las nuevas prácticas mediáticas en las comunidades de estudio expresan también una tensión entre las prioridades familiares, comunitarias e individuales en los grupos de jóvenes que están surgiendo. Estas tensiones están enmarcadas en procesos macro-sociales que reflejan cambios en las trayectorias de desarrollo asociadas, en parte por la escolaridad, por la migración y por otros procesos globales que juegan un papel central en la reconfiguración entre generaciones, como lo documentan varios estudiosos de la juventud. ${ }^{17}$

En el contexto de la región de estudio, estas reconfiguraciones generacionales son consistentes con la categoría de lo "etnojuvenil" propuesta por Cruz Salazar (2017) con relación a jóvenes tsotsiles, tseltales y choles. La autora argumenta a favor de una nueva etnicidad generacional asociada con el ach' kuxlejal (nueva vida), que se caracteriza por contenidos transversales que tienen como constante la distancia de la cultura juvenil con la costumbre comunitaria. ${ }^{18}$ Habla de modos de hacer y pensar orientados por la transculturalidad y alejados o en tensión con las generaciones previas. Entre los factores a los que alude están la escuela, el trabajo y el mercado de consumos; sin embargo, en su trabajo esta autora no contempla la comunicación virtual como parte del proceso de reelaboración identitaria juvenil. Por su parte, Zebadúa Carbonell incorpora la noción de "transculturalidad" como característica del universo de estudio de las identidades juveniles étnicas subrayando la relevancia de la apropiación mediática en términos de la construcción de "redes simbólicas más allá del territorio geográfico” (Zebadúa, 20llb: 44).

En la presente investigación se abona al estudio de las identidades juveniles étnicas aludiendo a la necesidad de incorporar a este campo las nuevas prácticas de la "comunicación digital". Para este fin se analizan las nuevas prácticas digitales como parte de la construcción de nuevos consumos, afectividades e identidades que pasan por la "vía virtual". Es importante subrayar que estos cambios están inscritos en procesos económicos y sociales más amplios que en las últimas décadas han tenido impacto en diversas escalas —familia, comunidad, región, nación y transnaciónde manera profund $a^{19} y$ que dan contexto a los procesos identitarios juveniles aquí analizados.

\section{Identidades colectivas en paisajes lingüísticos virtuales en redes sociales}

La presente investigación ha evolucionado a la par del uso de las tecnologías digitales y de las comunicaciones mediáticas en la comunidad de estudio, de manera longitudinal, entre 2012 y 2017. A medida que algunos jóvenes han ido adquiriendo teléfonos inteligentes, la conectividad los ha llevado a explorar los mundos virtuales en las redes sociales, lo que ha representado una nueva reconfiguración de identidades, ahora "identidades colectivas" de redes de grupos de pares (Castells et al., 2007) que presentan nuevos habitus (Bourdieu, 1977), esto es, nuevas prácticas y estilos compartidos de socialización y sociabilidad. Estas identidades son emergentes y contextuales, y pueden constituir subculturas de prácticas diversas en una variedad de páginas y sitios de grupos de distintas afiliaciones -musicales, religiosos, comunitarios, intelectuales, artesanos, entre otros-, locales y también translocales. Este paso representa también una refuncionalización del lenguaje en estas comunidades, normalmente anclado en interacciones cara a cara y arraigado territorialmente, frente al lenguaje móvil de 
los mensajes de texto y de las comunicaciones colectivas en las redes. Este cambio de paradigma plantea que la lengua es "móvil", no estática, fija ni territorial, tema que recientemente se está tratando desde la sociolingüística de la globalización en estudios de lenguaje y de migración (Blommaert, 2010). ${ }^{20}$

A lo largo del presente estudio se ha argumentado que las identidades juveniles se pueden estudiar con base en el conjunto de intercambios escritos en los paisajes virtuales que habitan los jóvenes. Como se ha expresado, estos mensajes "escritos" se despliegan en los espacios físicos y virtuales y, por su naturaleza dialógica, tienen los rasgos de intercambios orales. Se abordan de manera inductiva identificando microprocesos identitarios a partir de un análisis etnográfico y semiótico del paisaje contenido en cada página. En este sentido, constituyen un universo etnográfico semiótico por sí mismo que abre ventanas a procesos más amplios en curso, de lo micro-discursivo a lo macro-social. Como se ha expresado, el análisis se inscribe en la línea de la sociolingüística que analiza paisajes virtuales para documentar culturas juveniles globales, línea en la que se encuentra el trabajo de Mendoza Denton (2016), autora que ha investigado las formas de construir el localismo y la territorialidad en pandillas mexicanas en Estados Unidos, o estudios como los de Alim, Ibrahim y Pennycook (2008) sobre la cultura del hip hop global como expresión de identidades juveniles locales y globales. Léase, por ejemplo, la figura l, que contiene un intercambio de mensajes en la página de la canción "Dialecto" en YouTube del grupo de rap tsotsil Slajem K'op (la última palabra) de San Juan Chamula, Chiapas (ver figura 1).

Este paisaje virtual constituye un universo etnográfico por símismo. A primera vista, se observan los posicionamientos e ideologías lingüísticas e identitarias de los jóvenes de afiliación tsotsil que aparecen como interlocutores. Identificamos las elecciones de las lenguas (español o tsotsil), la autoadscripción de los hablantes (likemun tal ta Ch'enalvo': soy de Chenalhó), los juicios sobre el valor de su lengua ("tas pendejo, a nadie se le olvida su dialecto"), la afiliación a la música del grupo Slajem K'op, o la convocación en tsotsil de Chenalhó a "lo nuestro" en conversación con un grupo de origen chamula. Por otra parte, este paisaje no está arraigado en una comunidad física o histórica, sino que constituye un sistema sociolingüístico móvil, policéntrico, que refleja diversas escalas de diversidad (Blommaert, 2013: 11) en tanto reúne a jóvenes desde varios centros en un solo espacio de intercambio generado por un "centro de gravedad": la música en tsotsil de Slajem K'op.

En la página de YouTube del grupo Yibel Jme'tik Banamil se encuentra un paisaje virtual rico en encuentros identitarios y policéntricos que proporcionan información etnográfica en varias escalas (ver figura 2). Un usuario virtual llamado Kuxlejal (vida) agradece al grupo en tsotsil — con ortografía estándar de escritor- porque en su página muestran un video de "jteklumaltik Sots'leb" (nuestro pueblo de Zinacantán). El mensaje en tsotsil, por supuesto, construye lectores de tsotsil, quienes se incluyen como "nuestro pueblo". En los siguientes dos mensajes Salvador Hernández y Antonio Hernández Ton (piedra, apellido tsotsil) escriben en español con registro juvenil utilizando palabras como "chingón", "chido", "rola", "la raza" o "padre". Al final, Rosendo Pérez contribuye posicionándose explícitamente como originario de San Juan Chamula con el término incluyente "paisano": "arriba San Juan Chamula y San Pedro, la Tejeria, soy descendiente de Chamula y no me avergüenzo de donde soy, chido" (ver figura 2).

Esta página en la que interactúan cuatro personas es un concentrado de apuntamientos y posicionamientos identitarios que demuestra la emergencia "situada" de la identidad. Se observa en ella un sustrato comunitario tsotsil expresado desde un centro histórico, "nuestro pueblo Zinacantán”, pero también el encuentro sincrónico de otros centros: lenguaje juvenil en español, autoadscripción chamula y autoevaluación de este posicionamiento identitario: "no me avergüenzo". Este paisaje virtual ilustra el carácter policéntrico y superdiverso del lenguaje y de las identidades, en una sociolingüística que dialoga entre lo local y lo global. Nótese que en los casos estudiados las identidades colectivas se organizan alrededor de un centro de 
gravedad que evoca una identidad étnica juvenil tsotsil construida alrededor de un género musical, el etnorock tsotsil, en este caso representado por Yibel Jme'tik Banamil.

En las páginas de los dos grupos etnomusicales se aprecia un policentrismo - Zinacantán, Chenalhó, tsotsil, español juvenil- que gravita alrededor de un centro étnico identitario -el grupo musicalen un intercambio que cruza fronteras dialectales entre el tsotsil y el español. Los paisajes emanados de estas páginas de grupos de etnorock, en particular, "representan un tipo de consumo cultural que aparece como una práctica por la que se aglutinan muchos de los procesos de subjetivación juvenil en los contextos globales" (Zebadúa, López y Ascencio, 2017: 32). Estos procesos de subjetivación, sin embargo, se tejen desde diversos centros y escalas en un diálogo entre lo local y lo global.

En este sentido, los paisajes virtuales conforman repertorios de tipo lingüístico e identitario expresados en intercambios escritos situados, microscópicos, que se articulan con estructuras más amplias (Ahearn, 2001).

\section{Conclusiones}

Los estudios sobre la juventud en América Latina revelan la complejidad de un campo que cruza teorías, metodologías, paradigmas, poblaciones, etnicidades y prácticas culturales; en particular se enfrentan importantes retos por los diversos entrecruces entre lo étnico, lo juvenil, lo global, la tradición, la modernidad, lo urbano, lo rural, lo escolar y lo virtual, entre muchos más. ${ }^{21}$

El presente trabajo aporta al campo de las juventudes étnicas desde ángulos escasamente investigados en América Latina, el de la sociolingüística de la globalización y el de las literacidades digitales prácticas. Se partió del concepto de "paisaje (lingüístico) virtual" que se refiere a los mensajes "escritos" que se despliegan en los espacios virtuales (Blommaert, 2010; Mendoza-Denton, 2016). En particular se abordó el "paisaje virtual" en términos de: 1) tener una forma de escritura mediática, 2) ser el vehículo de formas y expresiones identitarias de culturas juveniles étnicas, y 3) constituir "repertorios identitarios" (Kroskrity, 1993). Es importante subrayar que en el corazón de este análisis la identidad y los repertorios de identidad se refieren al proceso por el cual: "las identidades son invocadas interactivamente por actores socioculturales a través del despliegue discursivo de los recursos lingüísticos" (Kroskrity, 1993: 222, énfasis de la autora). En esta investigación se subraya que las identidades de los jóvenes no se configuran sólo a partir de procesos culturales y políticos a gran escala, sino, de manera importante, al nivel local de las prácticas comunicativas emergentes y situadas. En este sentido, el estudio toma al lenguaje como un recurso primario en la configuración de identidades y como vehículo que intermedia la experiencia social local y la translocal (Bucholtz y Skapoulli, 2009: 2). Desde un análisis a nivel micro se examinaron unidades discursivas dialógicas escritas en intercambios virtuales, sea en mensajes de celular o en redes sociales. El nivel macro apunta al contexto cultural y político en el que se inscriben e inciden estos intercambios. Al tomar como unidad de análisis los intercambios discursivos, se plantea que la expansión de la conectividad en beneficio de sectores de la población de bajos recursos trae consigo también el desarrollo de nuevas destrezas de alfabetismos y tecnológicas. Entre otros puntos, se identificó el desarrollo de las "literacidades" (escrituras) digitales y su potencial como vehículo para la exploración y la elaboración de procesos y repertorios identitarios. En consecuencia, en este contexto la identidad consiste en un proceso emergente resultado de un desarrollo creativo e interpretativo inscrito y mediado textualmente.

Un punto central en este enfoque es la noción de "lenguaje móvil" en contraste con la noción convencional de lenguaje estático, arraigado territorialmente. El lenguaje móvil viaja en los medios digitales e imprime otro carácter a la construcción identitaria. Al examinar los paisajes virtuales en los mensajes de celular o en las páginas de las redes sociales se descubre el carácter policéntrico y superdiverso del lenguaje que dialoga entre lo local y lo global (Blommaert, 2010). Se 
identifican asimismo comunidades de práctica en las que convergen varios centros y diversidades, así como nuevas prácticas en la socialización y la sociabilidad juvenil étnica.

Cabe mencionar que los repertorios identitarios son flexibles y cambiantes. El lenguaje, los sujetos, los textos, las literacidades, las imágenes o las ideologías están en continuo movimiento, circulación y transformación. En este sentido, categorías fijas de identidad como nacionalidad, clase social, etnicidad y género se fragmentan, se erosionan, se entrecruzan y se reconfiguran (Bucholz y Skapoulli, 2009: 1). Por esta razón, es importante documentar a nivel local y etnográfico los microprocesos de producción identitaria para entender su emergencia y su conformación en diálogo con los procesos globales. Para finalizar, encontramos que los procesos globales no borran ni homogenizan los procesos identitarios locales porque lo local, a partir del sello de "lo tsotsil", "lo zinacanteco", "lo étnico" o "lo romántico", emerge con sus particularidades sociohistóricas y con proyecciones transculturales.

En consecuencia, la llegada de los celulares a las comunidades indígenas ha ofrecido una ventana etnográfica: el paisaje virtual, que permite rastrear la emergencia y la reconfiguración de las identidades individuales y colectivas de los jóvenes. Aparte de los procesos transculturales ya mencionados, cabe notar también la variedad de posibilidades de intersecciones entre lo juvenil y la costumbre en la comunicación digital. En el caso de los mensajes de texto románticos, se advierte un distanciamiento creciente entre las normas tradicionales de cortejo y los espacios crecientes de agencia juvenil en los procesos de elección de pareja. Por otra parte, en el caso de las prácticas mediáticas públicas se observan reapropiaciones de la tradición desde otros lugares que no necesariamente rompen con ésta, sino que la resignifican, como es el caso de lo etnomusical (Zebadúa, López y Ascencio, 2017).

En ambos casos, es un hecho que las prácticas discursivas en paisajes virtuales revelan el poder de la agencia emergente de los jóvenes para crear, resistir y transformar estructuras, tanto lingüísticas como sociales. Estas prácticas involucran recursos locales, translocales y globales que se tornan en vehículos para la apropiación de formas de capital social (Ahearn, 2001; Blommaert, 2008).

A medida que la conectividad se hace accesible a segmentos más amplios de la población joven, en los espacios de las redes se configuran y reconfiguran las identidades colectivas. Cada mensaje representa encuentros sincrónicos que reúnen escalas, centros múltiples y trayectorias diversas. Desde la escala local de la pareja que vive en la misma calle pero no puede hablar públicamente, a las escalas meso y macro de las redes donde se desdibuja o se refuerza lo étnico pronunciado en español: "tas pendejo, nadie olvida su dialecto", "...soy descendiente de chamula y no me avergüenzo de donde soy, chido".22

Para concluir, con el presente estudio se busca contribuir al campo de las culturas juveniles étnicas desde una lente que entiende las identidades juveniles mediáticas como procesos emergentes, situados, flexibles y negociados en las prácticas vehiculadas por el lenguaje, mostrando articulaciones con procesos más amplios en diversas escalas. En este sentido, la sociolingüística y la lingüística antropológica abonan al estudio del complejo y cambiante universo de las juventudes étnicas.

\section{Notas}

${ }^{1}$ Durante el período 2011-2015 la autora fue receptora de un financiamiento Ciencia Básica del CONACyT para realizar la investigación denominada "Cambios generacionales en la comunicación en Zinacantán y Chamula, Chiapas: un estudio intergeneracional e intrageneracional de competencias comunicativas y nichos de socialización (Proy\# 133492) a partir de la cual se investigó, entre otros temas, el uso del celular en estas localidades. Mi reconocimiento a Gabriela Rodríguez y Miguel Montiel por el procesamiento de datos. Igualmente se agradece a los jóvenes participantes de estas localidades cuyos nombres han sido cambiados para respetar la confidencialidad de los datos. Sin ellos esta investigación hubiera sido imposible. Wifi es un 
sustantivo común en español, incluido en 2011 en el DRAE (Diccionario de la Real Academia Española), que proviene del inglés, de la marca Wi-Fi. Se refiere a un mecanismo de conexión de dispositivos electrónicos de forma inalámbrica (véase https:dle.rae.es).

${ }^{2}$ Acrónimo para Short Message Service (servicio de mensajes cortos) en inglés, que corresponde a mensaje de texto prepagado en servicio de celular en México.

${ }^{3}$ WhatsApp es una aplicación de mensajería gratis disponible para teléfonos inteligentes que se usa con conexión a internet. Ver: https://play.google.com/store/ apps/details?id=com.whatsapp\&\&hl=es_419

${ }^{4}$ YouTube es un sitio web dedicado a compartir videos.

5 Ver también Alim, Ibrahim y Pennycook (2008) y Mendoza-Denton (2016).

${ }^{6}$ Ver también McLuhan (1962).

7 Por razones de confidencialidad se decidió usar el código KN, JN y TN para hacer referencia a estas tres comunidades en los ejemplos analizados en este trabajo.

${ }^{8}$ Ver: De León (1998, 2005, 2007, 2010, 2012a, 2012b, 2013, 2017a, 2017b, en prensa).

${ }^{9}$ YouTube es un sitio web dedicado a compartir videos.

${ }^{10}$ Los métodos para el estudio de la comunicación por celular se han basado en entrevistas o encuestas sobre el uso de éstos (Ling, 2004; Ruelas, 2014; Winocur, 2009a, entre otros), o por medio de la recolección de textos de mensajes de SMS con el reglamentario consentimiento de los usuarios (Good, 2012; McIntosh, 2010, entre otros).

"Ver; López, Ascencio y Zebadúa (2014) y Zebadúa, López y Ascencio (2017).

${ }^{12}$ Ver: Castells (1996), Bucholtz (2002), Ito, Matsuda y Okabe (2005), Urteaga (2007), Baron (2008), Subrahmanyam y Greenfield (2008), Urresti (2008), Murduchowicz (2008a, 2008b), Winocur (2009a, 2009b), Coleman (2010), McIntosh (2010), Ruelas (2010, 2014), García, Cruz y Castro Pozo (2012), Manago (2014), Manago, Guan y Greenfield (2015).

${ }^{13}$ Ver, por ejemplo: para África (McIntosh, 2010), para Jamaica (Horst y Miller, 2006), para México (De Angoitia y Ramírez, 2009; De León, 2017a, 2017b, en prensa; Pérez Ruiz, 2008; Ruelas, 2010, 2014; Winocur, 2009a, 2009b), para España (Sabaté, 2012) entre otros,

${ }^{14}$ Se usa el término de "literacidad" como traducción de literacy en inglés, ya que representa un espectro de prácticas de lecto-escritura que no se reducen al alfabetismo básico ni sólo a la escritura. Por esta razón se ha adoptado este término en el presente trabajo (ver Heath, 1983 en De León, 2010).

${ }^{15}$ Se utilizan iniciales para representar los nombres de los participantes a fin de proteger su confidencialidad, según acuerdo establecido con ellos. Las siglas entre paréntesisserefierenalascomunidades, decisión tomada por la investigadora para guardar confidencialidad también. El mensaje contiene dos líneas, la copia exacta del mensaje con su propia escritura y una versión en español estándar.

16 Sobre la tradición de pedir a la novia (jak'ol), ver Fishburne (1962, 1968, 1980); sobre fugarse con el novio, ver Collier (1990) y Flood (1994).

${ }^{17}$ Ver: Feixa (1998), Pérez y Urteaga (2004), Pérez Ruiz (2008), Reguillo (2010), Manago (2011, 2012), Urteaga (1998, 2007, 2008, 2009, 2011), Zebadúa-Carbonell (201la, 201lb), Cruz (2012, 2017), Neila (2012), entre otros.

${ }^{18}$ Ver también Neila Boyer (2012).

${ }^{19}$ Ver: Rusy Rus (2014), Rus (2009, 2010), Rus y Collier (2003).

${ }^{20}$ Ver también Bucholtz y Skapoulli (2009).

${ }^{21}$ Cruz-Salazar (2012, 2017), Feixa (1998), López, Ascencio y Zebadúa (2014), Manago (2011, 2012), Pérez Islas y Urteaga (2004), Pérez Ruiz (2008, 2017), Reguillo (1991, 2010), Rus (2009), Urteaga (1998, 2007, 2008, 2009, 2011), Zebadúa (2006, 20lla, 2011b), y Zebadúa, López y Ascencio (2017), entre otros

${ }^{22}$ Yibel Jme'tik Banamil, página en YouTube: https:// www.youtube.com/watch?v=F-13Elblu_E (consultada el 2 de febrero de 2016).

\section{Referencias}

Ahearn, Laura M. (2001). Invitations to Love: Literacy, Love Letters, and Social Change in Nepal. Ann Arbor: University of Michigan Press.

Alim, H. Samy, Awad Ibrahim y Alastair Pennycook (2008). Global Linguistic Flows: Hip Hop Cultures, Youth Identities, and the Politics of Language. Nueva York: Routledge, Taylor and Francis. 
Appadurai, Arjun (1996). Modernity at Large: Cultural Dimensions of Globalization. Minneapolis: University of Minnesota Press.

Baron, Noemi (2008). Always on: Language in an Online and Mobile World. Nueva York: Oxford University Press.

Blommaert, Jan (2008). Grassroots Literacy: Writing, Identity and Voice in Central Africa. Nueva York: Routledge.

Blommaert, Jan (2010). The Sociolinguistics of Globalization. Cambridge: Cambridge University Press.

Blommaert, Jan (2013). Superdiversity and Linguistic Landscapes. Reino Unido: Multilingual Matters.

Bourdieu, Pierre (1977). Outline of a theory of Practice. Cambridge: Cambridge University Press.

Bucholtz, Mary (2002). "Youth and Cultural Practice". En Annual Reviews in Anthropology, 31: 525-552.

Bucholtz, Mary y Elena Skapoulli (2009). "Introduction. Youth Language at the Intersection: from Migration to Globalization". En Pragmatics, 19(1): 1-16.

Castells, Manuel (1996). The Information Age.Economy, Society and Culture. Oxford, Malden, MA: Blackwell,

Castells, Manuel, Mireia Fernández-Ardèvol, Jack Linchuan Qiu y Araba Sey (2007). Mobile Communication and Society. A global Perspective. Cambridge, Mass.: Massachussetts Institute of Technology.

Clark, L.S. (2009). "Digital Media and the Generation Gap". En Information, Communication, and Society, 12(3): 388-407.

Coleman, E. Gabriella (2010). "Ethnographic Approaches to Digital Media”. En Annual Review of Anthropology, 39: 487-505.

Collier, George A. (1990). “Seeking Food and Seeking Money: Changing Productive Relations in a Highland Mexican Community". Discussion Paper 1l. United Nations Research Institute for Social Development [Instituto de las Naciones Unidas para el Desarrollo Social].

Cruz Salazar, Tania (2012). "El joven indígena en Chiapas: el re-conocimiento de un sujeto histórico". En LiminaR. Estudios Sociales y Humanísticos, X(2): 145-162.

Cruz Salazar, Tania (2017). "Lo etnojuvenil. Un análisis sobre el cambio sociocultural entre tsotsiles, tseltales y choles". En LiminaR. Estudios Sociales y Humanísticos, XV(1): 53-67.
Crystal, David (2008). Txtng: The Gr8 Db8. Oxford: Oxford University Press.

De Angoitia, Regina y Fernando Ramírez (2009). Strategic UseofMobilesin Latin America and the Caribbean [documento de trabajo]. México: Centro de Investigación y Docencia Económicas.

De León Pasquel, Lourdes (1998). "The Emergent Participant: Interactive Patterns of Socialization of Tzotzil (Mayan) Children". En Journal of Linguistic Anthropology, 8(2):131-161.

De León Pasquel, Lourdes (2005). La llegada del alma: lenguaje, infancia y socialización entre los mayas de Zinacantán. México: CIESAS, INAH, CONACULTA.

De León Pasquel, Lourdes (2007). "Parallelism, Metalinguistic Play, and the Interactive Emergence of Zinacantec Mayan Siblings' Culture". En Research on Language and Social Interaction 40(4): 405-436.

De León Pasquel, Lourdes (2010). Socialización, lenguajes y culturas infantiles. México: CIESAS.

DeLeón Pasquel,Lourdes (2012a). "Multiparty Participation Frameworks in Language Socialization”. En Alessandro Duranti, Elinor Ochs y Bambi Schieffelin (coords.), Handbook of Language Socialization, 81-112. Malden, MA, Blackwell.

De León Pasquel, Lourdes (2012b). "Reshaping Generational Boundaries and Selves: Authority and New Literacy Practices among Mayan Youth Peer Groups”.Annual Meetings of the American Anthropological Association [Reuniones anuales de la Asociación Americana de Antropología]. San Francisco, CA, 2012.

De León Pasquel, Lourdes (2013). “Changing Communication Ecologies Among Tzotzil Mayans: The Use of Cell Phones in Family Life". En Worskshop on Unseen Connections of the Ecologies of Cell Phones. Museo de Historia Natural del Instituto Smithsoniano, 28 de febrero a l de marzo de 2013, Washington, D.C.

De León Pasquel, Lourdes (2017a). "Las diversas caras del uso del teléfono celular en México". En Horizontum, $1 l$ de enero. Disponible en: http://www.horizontum. com/las-diversas-caras-del-uso-del-telefono-celularen-mexico/.

De León Pasquel, Lourdes (2017b). "Texting Amor: Emerging Intimacies in New Courtship Practices 
among Tzotzil Mayan Youth". En Ethos: Journal of the Society of Psychological Anthropology, vol. 45, núm. 4.

De León Pasquel, Lourdes (en prensa). "Medialects in the Creation of Mayan Peer Cultures: Romantic Texting as a new Literacy Practice". En J. Kuipers y J. Bell (eds), Linguistic and Material Intimacies of the Cellphone. Londres: Routledge.

Feixa, Carles (1998). El reloj de arena. Culturas juveniles en México, México: Causa Joven, SEP.

Fishburne Collier, Jane (1962). "Courtship and Marriage in Zinacantán”. Tesis de licenciatura en Antropología. Radcliff College, Cambridge, MA.

Fishburne Collier, Jane (1968). "Courtship and Marriage in Zinacantán”. En Middle American Research Institute, 25: 139-201.

Fishburne Collier, Jane (1980). "El noviazgo zinacanteco como transacción económica”. En Evon Vogt (ed.), Los zinacantecos. México: Sepsetentas.

Foth, M. y G. Hearn (2007). "Networked Individualism of Urban Residents: Discovering the Communicative Ecology in Inner-City Apartment Buildings". En Information, Communication \& Society, 10(5): 205-227

Flood, Marielle (1994). "Changing Patterns of Interdependence: the Effects of Increasing Monetization on Gender Relations in Zinacantán, México". En Research in Economic Anthropology, 15: 145-173.

García Canclini, Néstor, Francisco Cruz y Maritza Urteaga Castro-Pozo (2012). Jóvenes, culturas urbanas y redes digitales. Madrid: Ariel, Fundación Telefónica.

Good, Mary (2012). Modern Moralities, Moral Modernities: Ambivalence and Change among Youth in Tonga. Tesis de doctorado, Department of Anthropology. The University of Arizona.

Heath, Shirley B. (1983). Ways with Words: Language, Life, and Work in Communities and Classrooms. Cambridge: Cambridge University Press.

Horst A. Heather y Daniel Miller (2006). The Cell Phone: an Anthropology of Communication. Nueva York: Berg.

INEGI (Instituto Nacional de Estadística y Geografía) (2015). Principales resultados de la Encuesta Intercensal 2015. Chiapas. Disponible en: http://internet.contenidos.inegi. org.mx/contenidos/Productos/prod_serv/contenidos/ espanol/bvinegi/productos/nueva_estruc/inter_censal/ estados2015/702825079 (consultado el 7 de septiembre de 2017).

INEGI (Instituto Nacional de Estadística y Geografía) (2016). Encuesta Nacional sobre Disponiblidad y Uso de las Tecnologías de la Información en los Hogares (ENDUTIH). México: INEGI. Disponible en: http://www.beta.inegi. org.mx/contenidos/proyectos/enchogares/regulares/ dutih/2016/doc/dutih_presentacion.pdf (consultado en marzo de 2016).

Ito, Mitzuko, Misa Matsuda y Daisuke Okabe (coords.) (2005). Personal, Portable, Pedestrian: Mobile Phones in Japanese Life. Cambridge: MIT Press.

Kroskrity, Paul V. (1993). Language, History, and Identity: Ethnologic Studies of the Arizona Tewa. Arizona: University of Arizona Press.

Ling, Robert (2004). The Mobile Connection. The Cell Phone's Impact on Society. Amsterdam: Elsevier, Morgan Kauffman

López Moya, Martín de la Cruz, Efraín Ascencio Cedillo y Juan Pablo Zebadúa Carbonell (coords.) (2014). Etnorock. Los rostros de una música global en el Sur de México. México: CESMECA-UNICACH, Juan Pablos Editor.

Manago, Adriana M. (2011). "Shifting Meanings for Gender and the Family Among the Maya in Chiapas, México". Tesis de doctorado, Departamento de Psicología, UCLA.

Manago, Adriana M. (2012). "The New Emerging Adult in Chiapas, México: Perceptions of Traditional Values and Value Change among First-Generation Maya University Students". En Journal of Adolescent Research 27(6): 663-713.

Manago, Adriana (2014). "Identity Development in the Digital Age: The Case of Social Networking Sites". En K.C. Mc Lean y M. Syed (eds), The Oxford Handbook of Identity Development. Nueva York: Oxford University Press, pp. 508-524.

Manago, Adriana M., Shu-Sha Guan y Patricia Greenfield (2015). "New Media, Social Change, and Human Development from Adolescence through the Transition to Adulthood". En L.A. Jensen (ed.), The Oxford Handbook of Human Culture and Development. Nueva York: Oxford University Press, pp. 519-534. 
Mcintosh, Janet (2010). “Mobile Phones and Mipoho's Prophecy. The Powers and Dangers of Flying Language". En American Ethnologist, 37(2): 337-353.

McLuhan, Marshall (1962). The Gutenberg Galaxy: The Making of Typographic Man. Londres: Routledge \& Kegan Paul.

Mendoza Denton, Norma (2016). "Norteño and Sureño Gangs, Hip Hop, and Ethnicity in YouTube. Localism in California through Spanish Accent Variation". En H. Samy Alim, John R. Rickford y Arnetha F. Ball (coords.). Raciolinguistics. Oxford: Oxford University Press.

Murduchowicz, Roxana (coord.) (2008a). Los jóvenes y las pantallas. Nuevas formas de sociabilidad. Buenos Aires: Gedisa.

Murduchowicz, Roxana (coord.) (2008b). La generación multimedia. Significados, consumos y prácticas culturales de los jóvenes. México: Paidós.

Neila Boyer, Isabel (2012). “Ach' Kuxlejal: El nuevo vivir. Amor, carácter y voluntad en la modernidad tzotzil”. En Pedro Pitarch Ramón y Gemma Orobitg (comps.), Modernidades indígenas. Madrid: Iberoamericana, Vervuert, pp. 279-317.

Pérez Islas, J.A y Maritza Urteaga Castro-Pozo (coords.) (2004). Historias de los jóvenes en México: su presencia en el siglo XX. México: Secretaría de Educación Pública, Instituto Mexicano de la Juventud, Archivo General de la Nación.

Pérez Ruiz, Maya Lorena (coord.) (2008). Jóvenes indígenas y globalización en América Latina. México: Instituto Nacional de Antropología e Historia.

Pérez Ruiz, Maya Lorena (2017). "Las muchachas mayas de Yaxcabá, Yucatán”. En LiminaR. Estudios Sociales y Humanísticos, XV(1): 68-81.

Reguillo, Rossana (coord.) (2010). Los jóvenes en México. México: FCE, CONACULTA.

Ruelas, Ana Luz (2010). "El teléfono celular y las aproximaciones para su estudio". En Comunicación y Sociedad, 14: 142-167.

Ruelas, Ana Luz (2014). "El teléfono celular y los jóvenes sinaloenses. Adopción, usos y adaptaciones". En Comunicación y Sociedad, 21: 101-131.

Rus, Jan (2009). "La nueva ciudad maya en el Valle de
Jovel: urbanización rápida, comunidad y juventud maya en San Cristóbal de Las Casas". En Maro Estrada Saavedra (coord.), Chiapas después de la tormenta: estudios sobre economía, sociedad y política. Ciudad de México: El Colegio de México, COCOPA, Cámara de Diputados, pp. 169-219.

Rus, Jan (2010). The End of the Plantations and the Transformation of Indigenous Society in Highland Chiapas, México, 1974-2009. Tesis de doctorado, Universidad de California, Riverside.

Rus, Jan y George A. Collier (2003). "A Generation of Crisis in the Chiapas Highlands: The Tzotziles of Chamula and Zincacantán, 1970-2000”. En Jan Rus, Aída Hernández y Shannon Mattiace (coords.), Mayan Lives, Mayan Utopias. Lanham, MD: Rowman \& Littlefield Publishers, pp. 33-61.

Rus, Diane L. y Jan Rus (2014). "Trapped behind the Lines: the Impact of Undocumented Migration, Debt and Recession on a Tsotsil Community of Chiapas, Mexico, 2002-2012". En Latin American Perspectives, 196(41): 154-177.

Sabaté, María (2012). "A Sociolinguistic Analysis of Transnational SMS Practices. Non-Elite Multilingualism, Grassroots Literary and Social Agency among Migrant Populations in Barcelona”. En Lingvistice Investigationes, 35(2): 318-340.

Street, Brian V. (2000). Literacy Events and Literacy Practices: Theory and Practice in the New Literacy Studies. En Kathryn E. Jones y Marilyn Martin-Jones (coords.), Multilingual Literacies. Reading and Writing Different Worlds. Filadelfia: John Benjamins Publishing Company, pp. 17-29.

Subrahmanyam, K., y Patricia M. Greenfield (2008)". Communicating Online: Adolescent Relationships and the Media". En Future of Children: Children and Media Technology, 18: 119-146.

Urresti, Marcelo (2008). Ciberculturas juveniles. La Plata: La Crujía

Urteaga Castro-Pozo, Maritza (1998). Por los territorios del rock. Identidades juveniles y rock mexicano. México: NCA, Causa Joven-SEP.

Urteaga Castro-Pozo, Maritza (2007). La construcción juvenil de la realidad. Jóvenes mexicanos y contemporáneos. Tesis de doctorado, México, UAM-Iztapalapa. 
Urteaga Castro-Pozo, Maritza (2008). "Lo juvenil en lo étnico. Migración juvenil indígena en la sociedad contemporánea mexicana". En Revista Ponto e Vírgula, 4: 261-275.

Urteaga Castro-Pozo, Maritza (coord.) (2009). Juventudes, culturas, identidades y tribus juveniles en el México contemporáneo. Suplemento Diario de Campo, núm. 56 y Diario de Campo núm. 106, octubre-diciembre. México: CNCA, Instituto Nacional de Antropología e Historia.

Urteaga Castro-Pozo, Maritza (2011). La construcción juvenil de la realidad. Jóvenes mexicanos contemporáneos. México: UAM, Juan Pablos.

Winocur, Rosalía (2009a). "La exhibición de la intimidad como estrategía de inclusión social entre los jóvenes y adolescentes". En Entretextos, 7(19): 1-7.
Winocur, Rosalía (2009b). Robinson Crusoe ya tiene celular. La conexión como espacio de control de la incertidumbre. México: UAM, Siglo XXI.

Zebadúa Carbonell, Juan Pablo (201la). Culturas juveniles, identidades y globalización. Madrid: Editorial Académica Española.

Zebadúa Carbonell, Juan Pablo (2011b). "Cultura, identidades y transculturalidad. Apuntes sobre la construcción identitaria de las juventudes indígenas". En LiminaR. Estudios Sociales y Humanísticos, IX(1): 36-47.

Zebadúa Carbonell, Juan Pablo, Martin de la Cruz López Moya y Efraín Ascencio Cedillo (2017). "Juventudes, identidades y transculturación. Un acercamiento analítico al rock indígena en Chiapas". En LiminaR. Estudios Sociales y Humanísticos, XV(1): 29-41. 
Figura 1: Paisaje lingüístico en página YouTube del grupo de rap Slajem K’op

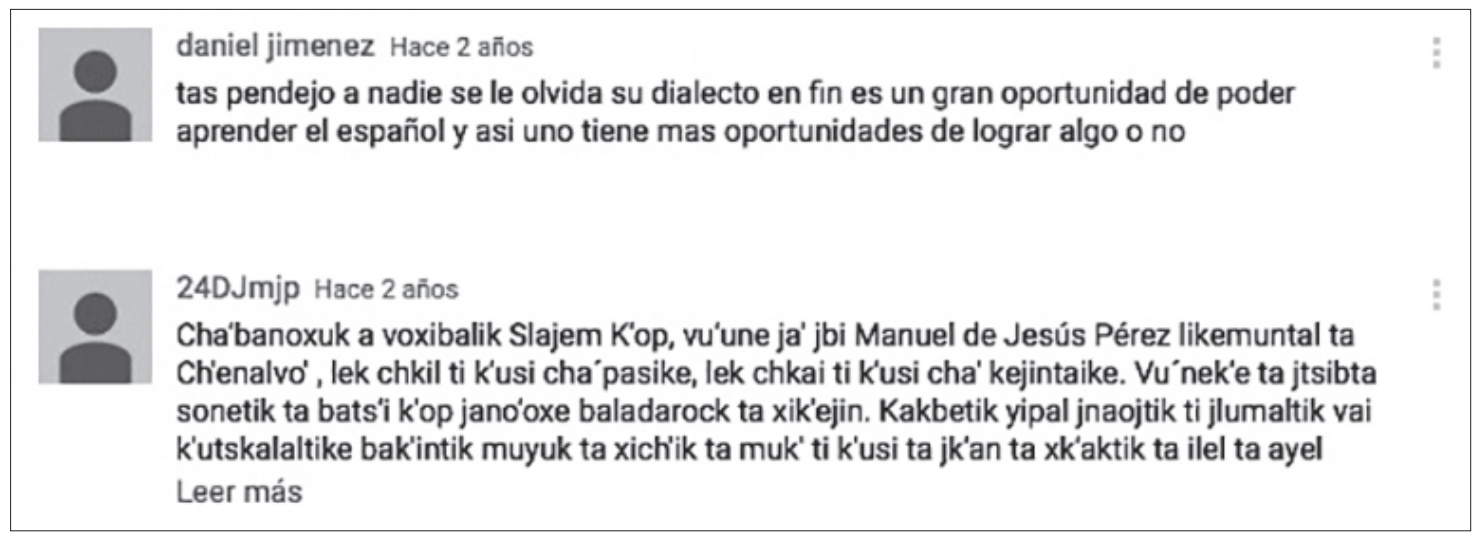

Fuente: Slajem K’op, página de YouTube: https://www.youtube.com/watch?v=sRB5aWyqopk (consultada el 2 de febrero de 2016).

Traducción: Saludos a los tres de Slajem K’op, yo me llamo Manuel de Jesús Pérez de Chenalhó, me gusta lo que hacen, me gusta lo que cantan, yo escribo letras de canciones en tsotsil para baladarock y canto. Echémosle ganas, sabemos que nuestros pueblos, nuestros paisanos, a veces no valoran lo que nosotros hacemos y expresamos.

Figura 2. Paisaje lingüístico en página de YouTube del grupo Yibel Jme’tik Banamil

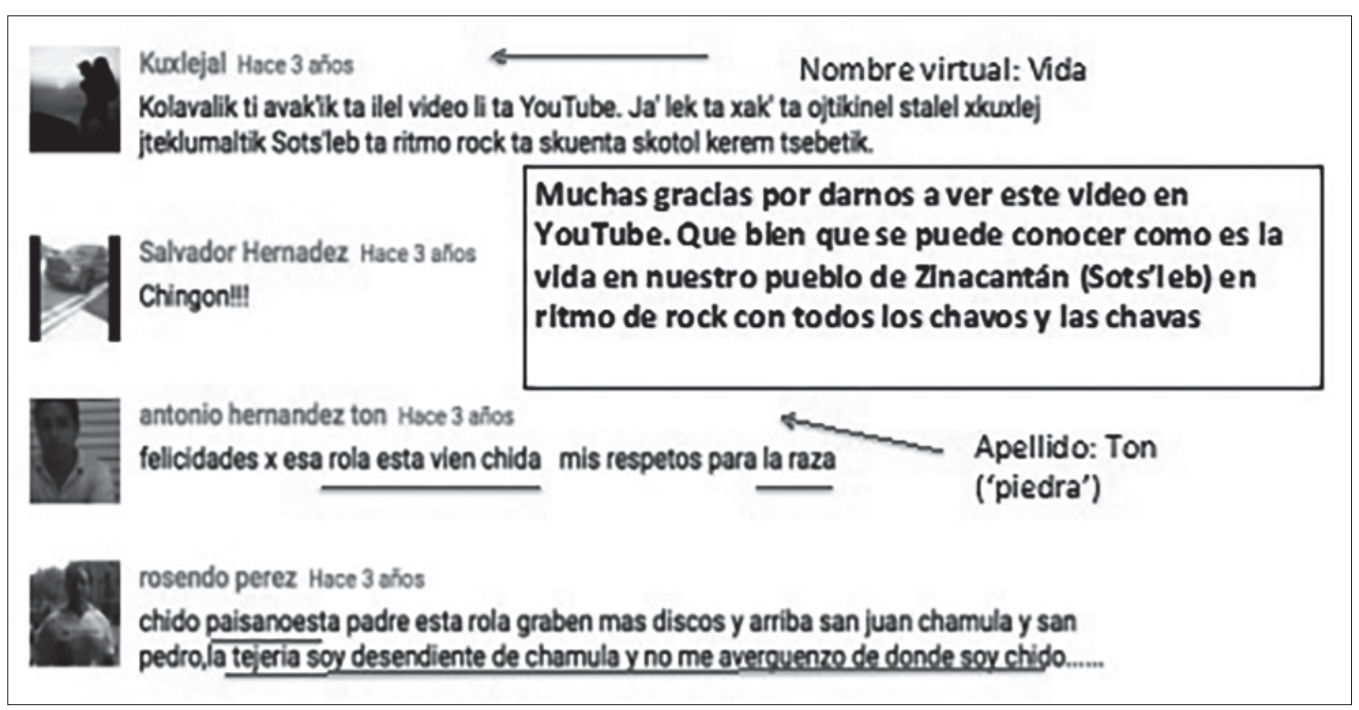

Fuente: Yibel Jmétik Banamil, página de YouTube: https://www.youtube.com/watch?v=F-I3Elb1u_E. 